\title{
Newly developed Compact Isolation Transformers for Signaling Networks
}

\author{
HITOSHI KIJIMA, CHIKASHI OKABAYASHI \\ Tokaigakuin University, Sankosha Inc. \\ JAPAN
}

\begin{abstract}
This paper describes the specifications of newly developed compact isolation transformers for signaling networks such as telecommunication installations and information installations. These networks can use isolation transformers to mitigate surges occurring on services. It means that isolation transformers are used to eliminate the affect of noise and common mode voltage. Also the isolation transformers provide lightning protection for these networks. As the specifications of conventional isolation transformers are not sufficient, small-sized isolation transformers were developed. The new isolation transformers offer high isolation withstand voltage $(50 \mathrm{kV}, 1.2 / 50 \mu \mathrm{s})$ with low insertion loss $(0.5 \mathrm{~dB})$ in the transmission frequency band of $500 \mathrm{~Hz}$ to $30 \mathrm{MHz}$. The weight is only $0.3 \mathrm{~kg}$ and the size is only $6 \times 6 \times 5 \mathrm{~cm}$.
\end{abstract}

Key-Words: isolation transformer, isolation withstand voltage, low insertion loss

Received: February 25, 2020. Revised: November 3, 2020, Accepted: November 24, 2020. Published: December 3, 2020.

\section{Introduction}

EMC technologies have been introduced in the articles [1]-[13]. One of EMC technologies to be considered is isolation transformers.

This paper describes the specifications of newly developed compact isolation transformers for signaling networks such as telecommunication installations and information installations. These networks can use isolation transformers to mitigate surges occurring on services.

Recommendation ITU-T K.95 gives test methods and preferred values for the isolation transformer surge parameters [14]. Recommendation ITU-T K.126 discusses isolation transformer parameters and how they influence the equipment common-mode surge [15]. IEC 61643-352 covers the application of surge isolation transformers that are used in telecommunication applications [16]. Even these documents provide basic parameters on isolation transformers, product design features and evaluation test results of them were not addressed. Therefore this paper describes product design features and evaluation test results of small-sized isolation transformers developed. These new isolation transformers include three types that are designed for low-speed $64 \mathrm{kHz}$ lines, medium-speed $1.5 \mathrm{MHz}$ and 2 $\mathrm{MHz}$ lines, and high-speed $6.3 \mathrm{MHz}$ and $8 \mathrm{MHz}$ lines.

These transformers offer high isolation withstand voltage $(50 \mathrm{kV}, 1.2 / 50 \mu \mathrm{s})$ with low insertion loss $(0.5 \mathrm{~dB})$ in the transmission frequency band of $500 \mathrm{~Hz}$ to $30 \mathrm{MHz}$.

\section{Need for development of small-sized isolation transformers}

Isolation transformers have been used mainly in hill-top base stations, where lightning damage is frequent. The comparisons of conventional and newly developed isolation transformers made by Sankosha [17] are listed in Table 1.

Table 1 Comparison of conventional and newly developed isolation transformers

\begin{tabular}{|l|l|l|}
\hline & Conventional & New developed \\
\hline Insertion loss & $1 \mathrm{~dB}$ & $0.5 \mathrm{~dB}$ \\
& $(3.4 \mathrm{kHz})$ & $(500 \mathrm{~Hz} \sim 30 \mathrm{MHz})$ \\
\hline Withstand voltage & $30 \mathrm{kV}(1.2 / 50 \mu \mathrm{s})$ & $50 \mathrm{kV}(1.2 / 50 \mu \mathrm{s})$ \\
\hline Weight & $10 \mathrm{~kg}$ & $0.3 \mathrm{~kg}$ \\
\hline Size & $10 \times 10 \times 10 \mathrm{~cm}$ & $6 \times 6 \times 5 \mathrm{~cm}$ \\
\hline
\end{tabular}

When isolation transformers are used in hill-top base stations, where there are generally only several cables, there is no problem of space for installing the transformers, each of which weighs $10 \mathrm{~kg}$ and is $10 \times 10$ $\times 10 \mathrm{~cm}$ in size. Also, the insertion loss is a large $1 \mathrm{~dB}$. Furthermore, the isolation withstand voltage against lightning surge is a low $30 \mathrm{kV}$.

On the other hand, within buildings, the isolation transformers should be smaller and lighter and to have lower insertion loss and higher isolation withstand voltage than conventional isolation transformers. It is necessary to develop new isolation transformers that satisfy the specifications described in the next section.

The performance of similar products other than Sankosha is inferior to that of new products.

A dedicated distribution frame was also developed to install the new isolation transformers with necessary function for terminating cables. 


\section{Specifications of the new isolation transformers}

Here, the specifications of the new isolation transformers are presented in detail.

\section{1 Insertion loss}

A total of five transmission rates are available for the metallic lines that are used for isolation transformers: 64 $\mathrm{kHz}, 1.5 \mathrm{MHz}$ and $2 \mathrm{MHz}$ for metal-sheathed balanced pair cable and $6.3 \mathrm{MHz}$ and $8 \mathrm{MHz}$ for coaxial cable.

In order for the insertion loss to satisfy the overall loss allocation for the entire signaling networks at those transmission rates, the insertion loss must be less than 0.5 $\mathrm{dB}$. Because it is difficult to meet this requirement for insertion loss of $0.5 \mathrm{~dB}$ over a broad frequency range using one isolation transformer, the frequency band is divided into three parts according to transmission rate as listed in Table 2 [18].

That is to say, there are three types of transformers, one for high-speed transmission at $6.3 \mathrm{MHz}$ or $8 \mathrm{MHz}$ over coaxial cable, one for medium-speed transmission at $1.5 \mathrm{MHz}$ or $2 \mathrm{MHz}$ over balanced pair cable, and one for low-speed transmission at $64 \mathrm{kHz}$ over balanced pair cable.

The simulation signals of conventional and new transformer (Low-speed transmission at $64 \mathrm{kHz}$ ) are shown in Fig.1.

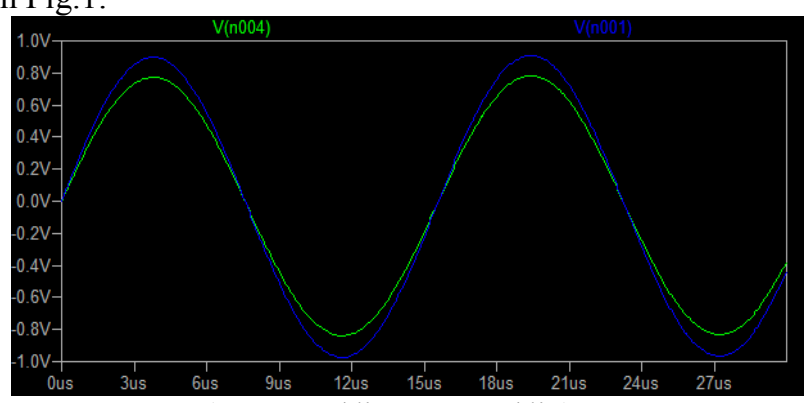

( X 3usec/div, Y 0.2V/div)

Blue line: new, Green line: conventional

Fig.1 Spice simulation signals of conventional transformer and new transformer

Table 2 Insertion loss of the new isolation transformers

\begin{tabular}{|l|c|l|c|}
\hline & $\begin{array}{c}\text { Transmission } \\
\text { rate }(\mathrm{Hz})\end{array}$ & $\begin{array}{l}\text { Frequency } \\
\text { band }(\mathrm{Hz})\end{array}$ & $\begin{array}{c}\text { Insertion } \\
\text { loss }(\mathrm{dB})\end{array}$ \\
\hline High-speed & $\begin{array}{c}6.3 \mathrm{M} \\
8 \mathrm{M}\end{array}$ & $100 \mathrm{k} \sim 30 \mathrm{M}$ & 0.5 \\
\hline Medium-speed & $\begin{array}{c}1.5 \mathrm{M} \\
2 \mathrm{M}\end{array}$ & $10 \mathrm{k} \sim 8 \mathrm{M}$ & 0.5 \\
\hline Low-speed & $64 \mathrm{k}$ & $0.5 \sim 400 \mathrm{k}$ & 0.5 \\
\hline
\end{tabular}

\section{2 Balance (LCL)}

The degree of balance is expressed by the Longitudinal Conversion Loss (LCL), which is the ratio for converting the voltage between a two-wire lines and earth (i.e., the common mode voltage) to the voltage between the wires (i.e., the differential voltage).

Table 3 LCL of the new isolation transformers

\begin{tabular}{|l|c|c|}
\hline & Frequency $(\mathrm{Hz})$ & LCL $(\mathrm{dB})$ \\
\hline Medium-speed & $10 \mathrm{k}$ & 85 \\
\hline Medium-speed & $1.5 \mathrm{M}$ & 50 \\
\hline Medium-speed & $2 \mathrm{M}$ & 45 \\
\hline Low-speed & 500 & 85 \\
\hline Low-speed & $64 \mathrm{k}$ & 60 \\
\hline Low-speed & $400 \mathrm{k}$ & 50 \\
\hline
\end{tabular}

The LCL values for the isolation transformers that are used for medium-speed transmission over balanced pair cable and that of the transformers for use with low-speed lines must be equal to or greater than the characteristics of cables as listed in Table 3 [18].

\subsection{Characteristic impedance}

The characteristic impedance of the isolation transformers must be the same as that of the cables in order to reduce signal reflection. For that reason, a tolerance of -10 to $+10 \%$ is allowed in the characteristic impedance specification as listed in Table 4 [18].

Table 4 Characteristic impedance of the new isolation transformers

\begin{tabular}{|l|c|c|}
\hline & $\begin{array}{l}\text { Characteristic } \\
\text { impedance }(\Omega)\end{array}$ & Tolerance (\%) \\
\hline High-speed & 75 & $-10 \sim+10$ \\
\hline $\begin{array}{l}\text { Medium- } \\
\text { speed }\end{array}$ & 110 & $-10 \sim+10$ \\
\hline Low-speed & 110 & $-10 \sim+10$ \\
\hline
\end{tabular}

\section{4 Isolation withstand voltage}

In the case of the maximum current flow of $200 \mathrm{kA}$ caused by a direct lightning strike on the building, the LEMP (Lightning Electro-Magnetic Pulse) generates an induced voltage of $50 \mathrm{kV}$ [19]-[21]. Therefore the isolation withstand voltage specification is set at $50 \mathrm{kV}$.

\section{5 Surge transfer ratio}

The surge transfer ratio means that common mode lightning surge voltage is transferred from the primary windings to the secondary windings. It is determined to be $1 / 50$ from the consistency of the insertion loss and the isolation withstand voltage.

\section{Product design features of the new isolation transformers}

The problems involved in the development of the new isolation transformers were to reduce the insertion loss and 
to achieve a high isolation withstand voltage while maintaining small-size and light weight.

The insulation has physical paths such as winding insulating material between the two windings. Surface distance should be set so that the maximum expected voltage difference do not cause surface flashover. Solid insulation thickness should be set so that the maximum expected voltage difference does not cause breakdown.

To overcome those problems, the points listed below were implemented so as to achieve the low insertion loss of 0.5 $\mathrm{dB}$ for the respective transmission speeds while maintaining a high withstand voltage of $50 \mathrm{kV}$ against lightning surge.

(1) Photographs of the isolation transformers are shown in Fig. 2. The isolation transformer shown in the upper part of the figure is the one that has conventionally been used in hill-top base stations. This conventional isolation transformer has metal case and screw-type terminals.

The isolation transformers shown in the lower part of Fig. 2 are the newly developed ones. From left to right, they are the high-speed, medium-speed, and low-speed transformers. These isolation transformers have plastic cases. The transformer terminals are BNC connectors for the high-speed unit and spring-pressure wire connectors for the medium-speed and low-speed units. The high-speed, medium-speed and low-speed transformers respectively weigh $220 \mathrm{~g}, 230 \mathrm{~g}$ and $310 \mathrm{~g}$, which is $1 / 30$ comparing to that of conventional isolation transformer $(10 \mathrm{~kg})$. The size, too, has been reduced, with the largest low-speed isolation transformers being $6 \times 6 \times 5 \mathrm{~cm}$, is $1 / 5$ comparing to that of conventional isolation transformer $(10 \times 10 \times 10 \mathrm{~cm})$.

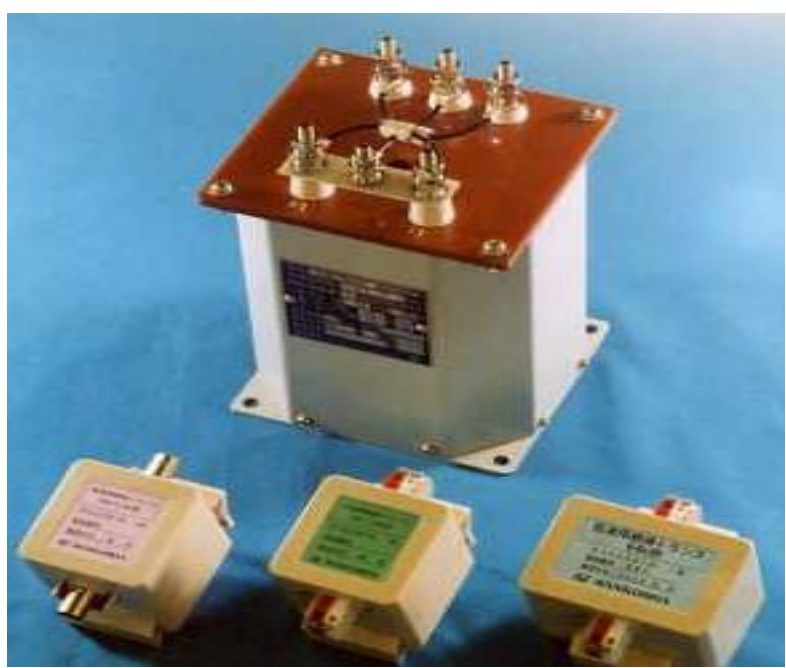

(a) Upper: conventional, (b) Lower : newly developed

\section{Fig.2 External appearance of transformers}

(2) To ensure an insertion loss of $0.5 \mathrm{~dB}$ or less over a wide range, a Mn-Zn ferrite magnetic core, which has a high magnetic permeability and low high-frequency loss, was used. The core configuration was the E-I shape because of the requirement for high isolation withstand voltage.
(3) To achieve small size and light weight, the conventional metal case for housing was replaced with a plastic case and the conventional screw-type terminals were replaced with $\mathrm{BNC}$ connectors in the case of the high-speed transformers and spring-pressure wire connectors in the case of the medium-speed and low-speed transformers.

(4) To ensure a high isolation withstand voltage over a broad frequency range, a thin polyester film was used to insulate the windings and multiple layers were used to reduce the defects in the film. Moreover, a two-liquid urethane resin was used as a filler material and a vacuum was applied to eliminate air bubbles.

(5) Fig.3 shows the structure of the new isolation transformers. To prevent surface flashover between the cable terminals of the transformer and the metal frame of the distribution frame, a plastic threshold plate was placed so as to cover the lower half of the BNC connectors of the high-speed insulating transformers. For the medium-speed and low-speed isolation transformers, spring-pressure terminals were used to prevent surface flashover from the terminals and the metal frame so as to make the surface distance at least $50 \mathrm{~mm}$ as shown in Fig.3. In this way, an isolation withstand voltage of $50 \mathrm{kV}$ against lightning surge was achieved.

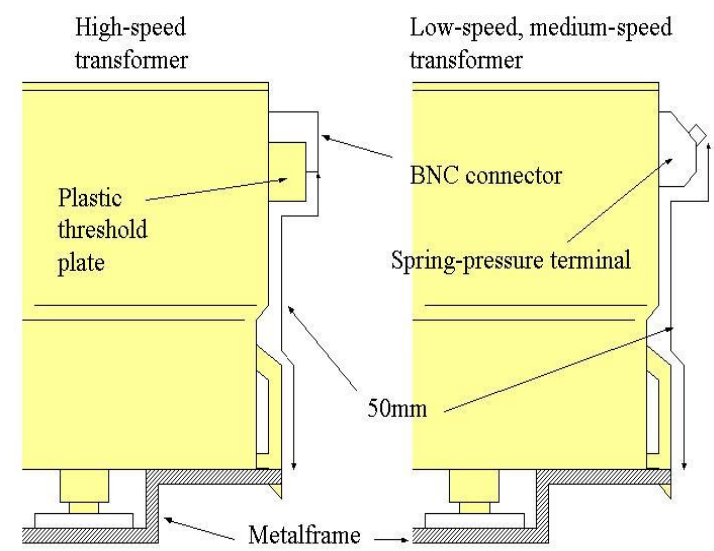

Fig.3 Structure of the new isolation transformers

(6) The new isolation transformers mounted in the distribution frame are shown in Fig. 4. The size of the newly developed distribution frame is $795(\mathrm{~W}) \times 600$ (D) $\times 1800$ (H) $\mathrm{mm}$. This distribution frame can accommodate 120 medium-speed isolation transformers or 80 high-speed or low-speed isolation transformers. This distribution frame also allows terminating cables. 


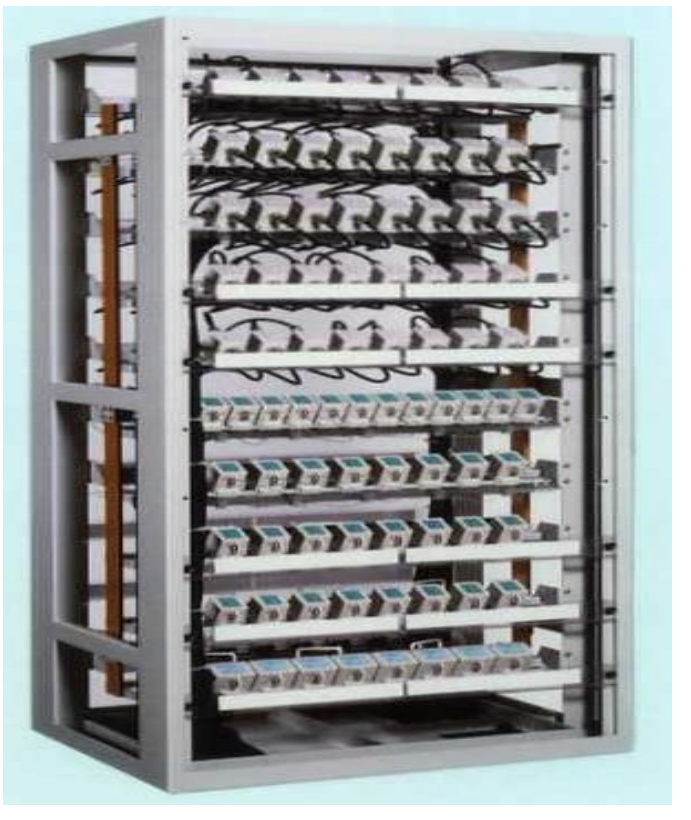

Fig.4 Distribution frame developed for the new isolation transformers

\section{Electrical evaluation test results of the new isolation transformers}

In this section, the electrical evaluation test results of the new isolation transformers are described.

\subsection{Insertion loss}

The insertion loss of the high-speed, medium-speed, and low-speed isolation transformers were measured using the circuit shown in Fig. 5. LM (Level Meter) is a kind of network analyzer to measure the output signal level in $\mathrm{dB}$.

The insertion loss is defined as a ratio of the signal level without the transformer to the signal level with the transformer installed.

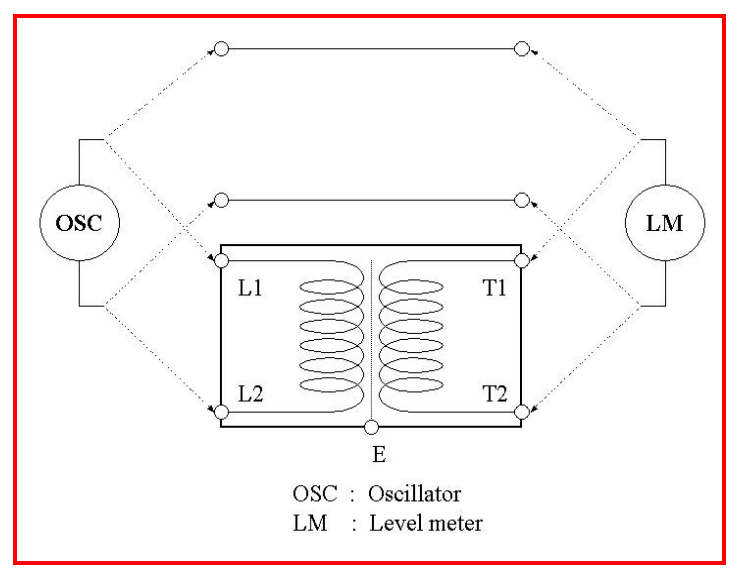

Fig.5 Circuit for measuring insertion loss

The measured frequency characteristics of the high-speed isolation transformers are presented in Fig. 6.
The measured values of the insertion loss of all isolation transformers are listed in Table 5. The required value of 0.5 $\mathrm{dB}$ insertion loss was satisfied by all over the entire frequency band.

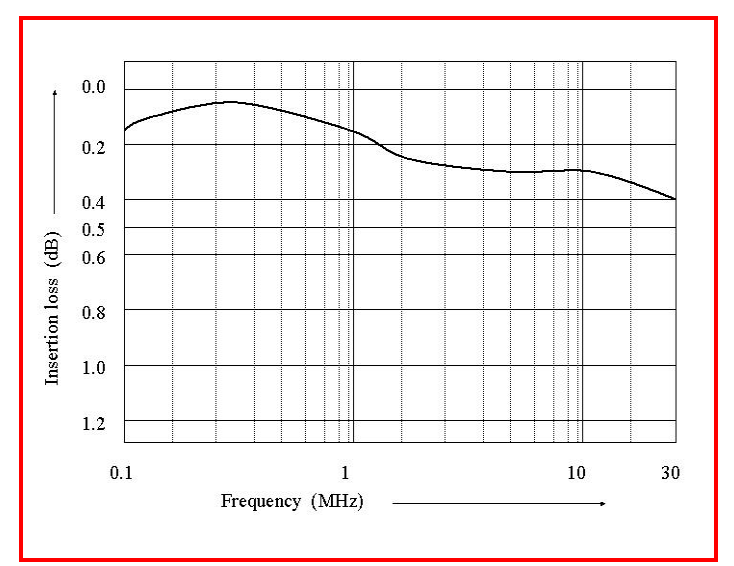

Fig.6 Frequency characteristic of insertion loss for high-speed isolation transformer

Table 5 Measured values of the insertion loss

\begin{tabular}{|l|c|c|}
\hline & Frequency $(\mathrm{Hz})$ & Insertion loss $(\mathrm{dB})$ \\
\hline High-speed & $100 \mathrm{k}$ & 0.15 \\
\hline High-speed & $8 \mathrm{M}$ & 0.28 \\
\hline High-speed & $30 \mathrm{M}$ & 0.40 \\
\hline Medium-speed & $10 \mathrm{k}$ & 0.28 \\
\hline Medium-speed & $2 \mathrm{M}$ & 0.12 \\
\hline Medium-speed & $8 \mathrm{M}$ & 0.26 \\
\hline Low-speed & 500 & 0.35 \\
\hline Low-speed & $64 \mathrm{k}$ & 0.20 \\
\hline Low-speed & $400 \mathrm{k}$ & 0.44 \\
\hline
\end{tabular}

\subsection{Balance (LCL)}

The LCL measuring circuit is shown in Fig.7 and the measured values are listed in Table 6.

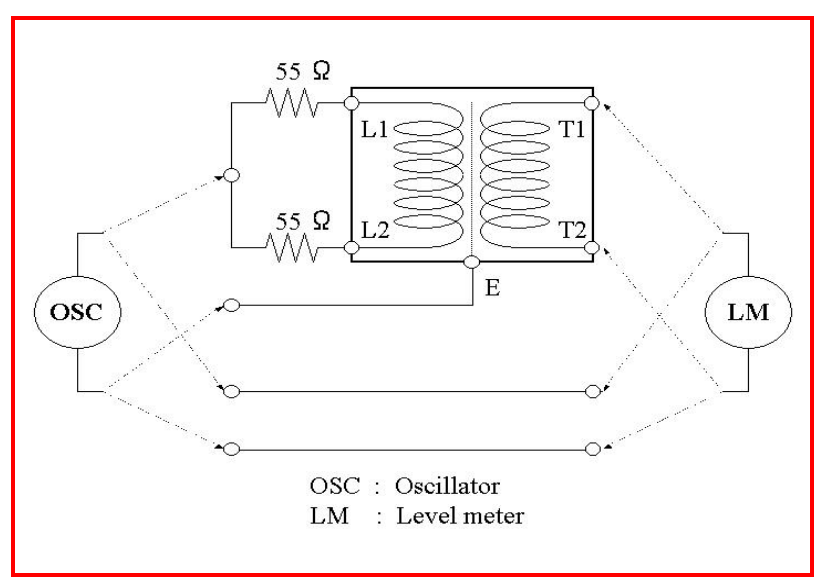

Fig.7 Circuit for measuring LCL 
Table 6 Measured values of $L C L$

\begin{tabular}{|l|c|c|}
\hline & Frequency $(\mathrm{Hz})$ & LCL $(\mathrm{dB})$ \\
\hline Medium-speed & $10 \mathrm{k}$ & 91 \\
\hline Medium-speed & $1.5 \mathrm{M}$ & 66 \\
\hline Medium-speed & $2 \mathrm{M}$ & 51 \\
\hline Low-speed & 500 & 94 \\
\hline Low-speed & $64 \mathrm{k}$ & 86 \\
\hline Low-speed & $400 \mathrm{k}$ & 73 \\
\hline
\end{tabular}

The required values of LCL were satisfied by all of the transformers over the entire frequency band.

\subsection{Characteristic impedance}

The circuit for measuring the characteristic impedance is shown in Fig.8.

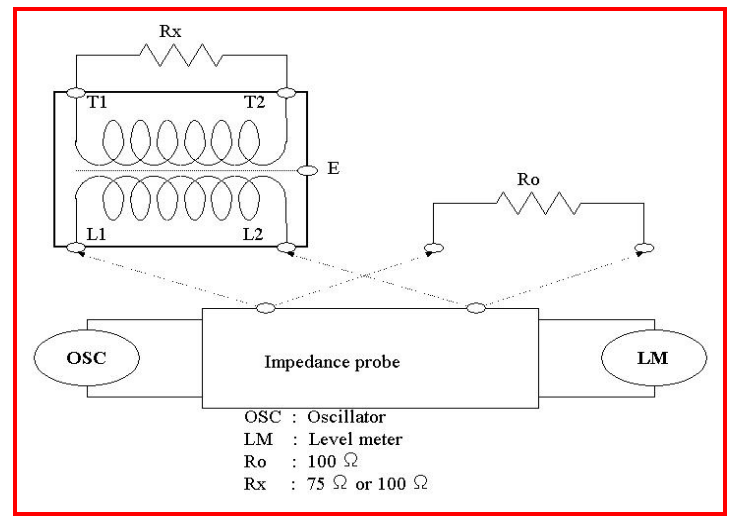

Fig.8 Circuit for measuring characteristic impedance

The measured characteristic impedance values are listed in Table 7. The measured characteristic impedance values of each of the isolation transformers deviated somewhat from the characteristic impedance value of $75 \Omega$ for the high-speed isolation transformer and the $110 \Omega$ value for the medium-speed and low-speed isolation transformers, but the deviation in the characteristic impedance values were from -9 to $+9 \%$, within the -10 to $+10 \%$ tolerance of the specification.

Table 7 Measured values of the characteristic impedance

\begin{tabular}{|l|c|c|}
\hline & Frequency $(\mathrm{Hz})$ & $\begin{array}{l}\text { Characteristic } \\
\text { impedance }(\Omega)\end{array}$ \\
\hline High-speed & $100 \mathrm{k}$ & 71 \\
\hline High-speed & $8 \mathrm{M}$ & 71 \\
\hline High-speed & $30 \mathrm{M}$ & 71 \\
\hline Medium-speed & $10 \mathrm{k}$ & 101 \\
\hline Medium-speed & $2 \mathrm{M}$ & 110 \\
\hline Medium-speed & $8 \mathrm{M}$ & 118 \\
\hline Low-speed & 500 & 109 \\
\hline Low-speed & $64 \mathrm{k}$ & 114 \\
\hline Low-speed & $400 \mathrm{k}$ & 120 \\
\hline
\end{tabular}

\subsection{Isolation withstand voltage}

The method for measuring the isolation withstand voltage is illustrated in Fig.9.

The voltage across the primary windings and the secondary windings was increased in $0.2 \mathrm{kV}$ steps up to 55 $\mathrm{kV}(1.2 / 50 \mu \mathrm{s})$ and the voltage just prior to failure of the insulation was taken to be the isolation withstand voltage. The measured values of the isolation withstand voltage are listed in Table 8.

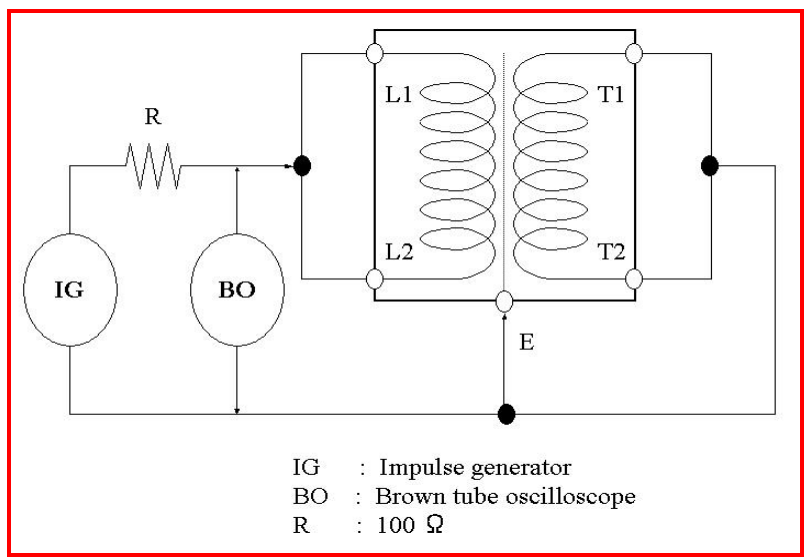

Fig.9 Circuit for measuring isolation withstand voltage

The measured isolation withstand voltage for each of the isolation transformers were in the range of 50.2 to $53.4 \mathrm{kV}$, exceeding the required value of $50 \mathrm{kV}$.

Table 8 Measured values of the isolation withstand voltage

\begin{tabular}{|l|c|c|}
\hline & Sample No. & Voltage $(\mathrm{kV})$ \\
\hline High-speed & 1 & 52.6 \\
\hline High-speed & 2 & 51.8 \\
\hline High-speed & 3 & 53.4 \\
\hline Medium-speed & 1 & 50.2 \\
\hline Medium-speed & 2 & 50.6 \\
\hline Medium-speed & 3 & 50.6 \\
\hline Low-speed & 1 & 51.0 \\
\hline Low-speed & 2 & 51.4 \\
\hline Low-speed & 3 & 51.4 \\
\hline
\end{tabular}

\section{5 Surge transfer ratio}

The surge transfer ratio is expressed by the common mode voltage between a two-wire lines and earth. And this surge transfer is caused by capacitive coupling between primary windings and secondary windings. These transformers have a screen between the primary windings and the secondary windings in order to eliminate this capacitive coupling. The surge transfer ratio measuring circuit is shown in Fig. 10.

A surge voltage of $10 \mathrm{kV}(1.2 / 50 \mu \mathrm{s})$ was applied to the primary side and the voltage generated on the secondary 
side was measured. The surge transfer ratio was obtained from the ratio of this input voltage and output voltage. Example of measured input voltage and output voltage waveforms are shown in Fig. 11.

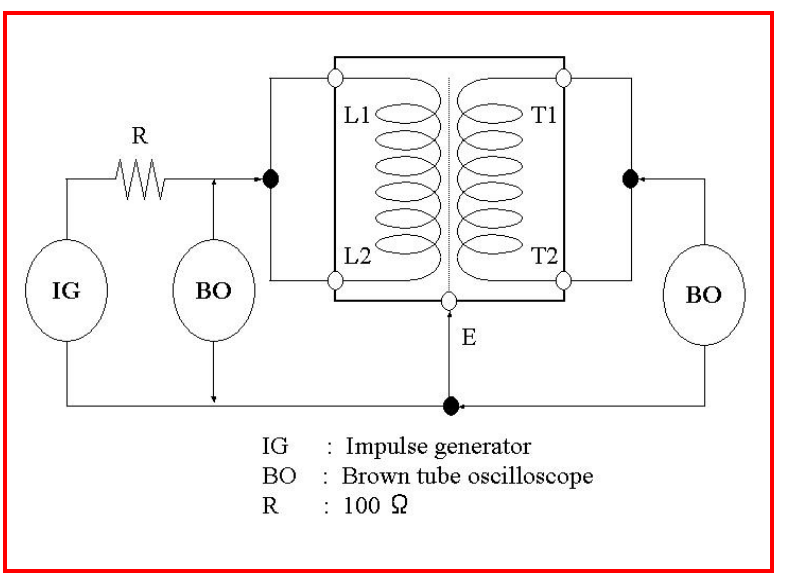

Fig.10 Circuit for measuring surge transfer ratio

For the input voltage of $10 \mathrm{kV}(\mathrm{CH} 1)$, the output voltage is $194 \mathrm{~V}(\mathrm{CH} 2)$, giving a surge transfer ratio of $1 / 52$.

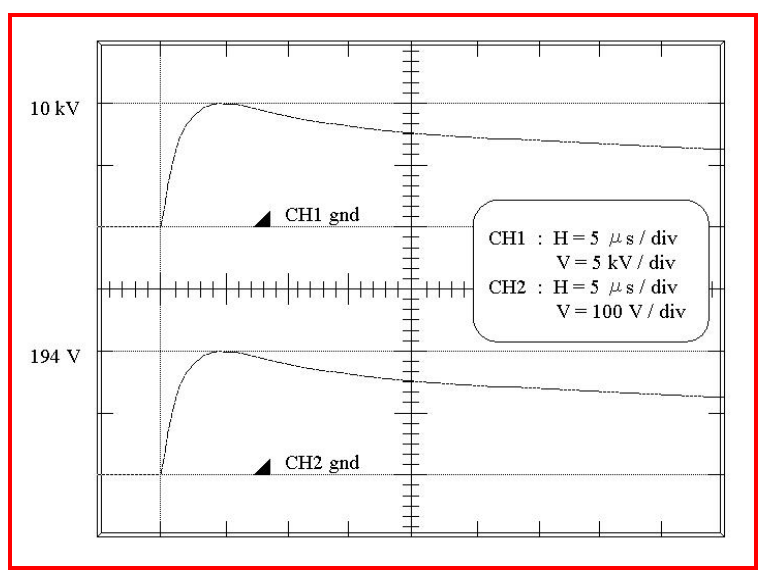

Fig.11 Example of measured input voltage and output voltage waveforms

Table 9 Measured values of the surge transfer ratio

\begin{tabular}{|l|c|c|}
\hline & Sample No. & Ratio \\
\hline High-speed & 1 & $1 / 52$ \\
\hline High-speed & 2 & $1 / 54$ \\
\hline High-speed & 3 & $1 / 53$ \\
\hline Medium-speed & 1 & $1 / 63$ \\
\hline Medium-speed & 2 & $1 / 66$ \\
\hline Medium-speed & 3 & $1 / 65$ \\
\hline Low-speed & 1 & $1 / 97$ \\
\hline Low-speed & 2 & $1 / 88$ \\
\hline Low-speed & 3 & $1 / 95$ \\
\hline
\end{tabular}

The measured values of the surge transfer ratio are listed in Table 9. The measured surge transfer ratios for the high-speed, medium-speed and low-speed isolation transformers are in the range of $1 / 52$ to $1 / 97$, satisfying the required value of $1 / 50$.

\section{Conclusion}

We developed small-sized isolation transformers for signaling networks such as telecommunication installations and information installations.

These new isolation transformers include three types that are designed for low-speed $64 \mathrm{kHz}$ lines, medium-speed 1.5 $\mathrm{MHz}$ and $2 \mathrm{MHz}$ lines, and high-speed 6.3 $\mathrm{MHz}$ and $8 \mathrm{MHz}$ lines. By implementing the design features listed below, we have achieved the high isolation withstand voltage of $50 \mathrm{kV}$ while maintaining insertion loss of $0.5 \mathrm{~dB}$ for the respective transmission speeds.

The weight is only $0.3 \mathrm{~kg}$ and the size is only $6 \times 6 \times 5 \mathrm{~cm}$.

(1)To ensure an insertion loss of $0.5 \mathrm{~dB}$ or less over a wide range, a $\mathrm{Mn}-\mathrm{Zn}$ ferrite magnetic core, which has a high magnetic permeability and low high-frequency loss, was used. The core configuration was the E-I shape because of the requirement for high isolation withstanding voltage.

(2)To achieve small size and light weight, the conventional metal case was replaced with a plastic case and the conventional screw-type terminals were replaced with BNC connectors in the case of the high-speed transformers and spring-pressure wire connectors in the case of the medium-speed and low-speed transformers.

(3)To ensure a high isolation withstand voltage while maintaining broadband frequency characteristics, a thin polyester film was used to insulate the windings and multiple layers were used to reduce the defects in the film. Moreover, a two-liquid urethane resin was used as a filler material and a vacuum was applied to eliminate air bubbles.

(4)To prevent surface flashover between the cable terminals of the transformer and the metal frame of the distribution frame, a plastic threshold plate was placed so as to cover the lower half of the BNC connectors of the high-speed isolation transformers. For the medium-speed and low-speed isolation transformers, spring-pressure terminals were used to prevent surface flashover from the terminals and the metal frame so as to make the surface distance at least $50 \mathrm{~mm}$. In this way, an isolation withstand voltage of $50 \mathrm{kV}$ against lightning surge was achieved.

(5) A dedicated distribution frame was also developed to install the new isolation transformers with necessary function for terminating cables. This distribution frame can accommodate 120 medium-speed isolation transformers or 80 high-speed or low-speed isolation transformers.

(6) As a future research, we would like to develop isolation transformers for much more high frequency signaling networks. 


\section{References:}

[1]H. Kijima, The current and magnetic field distribution generated by direct lightning strikes on buildings using FEM analysis, Engineering World, Vol.2, pp.120-127, 2020

[2]H. Kijima, K.Ochi, Pulse shaping method using bridge tap for fast transient burst test generator, WSEAS Transactions on electronics, Vol.10, pp.94-100, 2019

[3] H. Kijima, T.Hattori, Estimation results on the location error when using cable locator, WSEAS Transactions on systems, Vol.15, pp. 11-18, 2016

[4]K.Takato, H.Kijima, Power line communication degradation caused by surge protective device, IEEJ Transactions on communications, Vol.135, No.2, pp. 181-190, 2015

[5]K.Murakawa, H.Kijima, Earth resistance tester developed using resonant circuit technology with no auxiliary electrode, WSEAS Transactions on communications, Vol.13 pp. 484-493, 2014

[6]K.Murakawa,H.Kijima, Normalized power spectrum analysis based on LPC using time integral, WSEAS Transactions on communications, Vol.13 pp. 466-475, 2014

[7]H. Kijima,K.Ochi, Proposal of double voltage generator using four coaxial cables, International Journals of circuits, Issue 1, Vol.8, pp. 30-37, 2014

[8]H. Kijima,K.Ochi, High voltage pulse generator using normal cables, WSEAS Transactions on circuits and systems applications, engineering \& development, Issue 12, Vol.12 pp. 366-375, 2014

[9]H. Kijima, K.Murakawa, Lightning surge response improvement by combinations of varistors and GDTs, WSEAS Transactions on power systems, Issue 2, vol. 7, pp60-69, 2012

[10]H. Kijima, K.Takato, K. Murakawa, Lightning protection for gas-pipelines installed under the ground, International Journal of systems, Issue 1, vol. 5, pp117-126, 2011

[11]H. Kijima, T. Hasegawa, Electrical force analyzed results on switchgear of disconnector for overvoltage protector, WSEAS Transactions on power systems, Issue 1, vol. 5, pp32-41, 2010

[12] H. Kijima, M. Shibayama, Circuit breaker type disconnector for over voltage protector, WSEAS Transactions on power systems, Issue 5, vol. 4, pp167-176, 2009

[13]H. Kijima, A development of earth resistance estimation instrument, International Journal of geology, Issue 4, vol. 3, pp112-116, 2009

[14] Recommendation ITU-T K.95, Surge parameters of isolating transformers used in telecommunication devices and equipment, 2016

[15] Recommendation ITU-T K.126, Surge protective component application guide - High frequency signal isolation transformers, 2017
[16] IEC 61643-352, Components for low-voltage surge protection - Part 352: Selection and application principles for telecommunications and signaling network surge isolation transformers, 2018

[17]Sankosya , https://www.sankosha.co.jp, 2020

[18] Transmission Line Design Manual, Bureau of reclamation issued by ANSI, 2019

[19] IEC 62305-3, Protection against lightning, Physical damage to structures and life hazard, 2010

[20] IEC 62305-4, Protection against lightning, Electrical and electronic systems within structures, 2010

[21] S. Shivalli, Lightning effects and protection of structures, IOSR JEEE, Vol.11, Issue 3, pp44-50, 2016

\section{Creative Commons Attribution License 4.0 (Attribution 4.0 International, CC BY 4.0)}

This article is published under the terms of the Creative Commons Attribution License 4.0 https://creativecommons.org/licenses/by/4.0/deed.en US 